\title{
The ideal free distribution in humans: An experimental test
}

\author{
M. B. C. SOKOLOWSKI \\ Université de Picardie-Jules Vernes, Amiens, France \\ F. TONNEAU \\ University of Guadalajara, Guadalajara, Mexico \\ and \\ E. FREIXA I BAQUÉ \\ Université de Picardie-Jules Vernes, Amiens, France
}

\begin{abstract}
How the distribution of resources affects the spatial distribution of animals is a central concern of behavioral ecology. One influential model relating population dynamics to individual foraging behavior is that of ideal free distribution (Fretwell \& Lucas, 1970). This model assumes foragers of equal competitive abilities, moving freely from one habitat to another; the choices made by each individual subject are supposed to equalize gains across habitats. The resulting distribution at the group level, or ideal free distribution, has been tested with various animal species. Here we report an experimental test with human subjects competing for money. The results approximate those predicted by the ideal free model, the degree of approximation being consistent with that obtained in other species. This similarity of results supports the application of behavioral ecology models to human performance.
\end{abstract}

The ideal free model (Fretwell \& Lucas, 1970) has been proposed by behavioral ecologists to account for the distribution of animals in their environment (see Sutherland, 1996). Resources such as food or mates often occur in different habitats, or sites, among which foraging animals travel. The main insight behind the ideal free model is that an individual's gain in a site depends not only on the amount of resources available in this site, but also on the number of foragers exploiting them; as this number increases, the gain for each individual declines (e.g., Hassell \& Varley, 1969). Assuming that the foraging animals are of equal competitive abilities, that they move freely from one site to another and optimize their resource intake by choosing the site with the highest gain, foragers will distribute themselves among sites until, at the equilibrium, all sites provide the same gain per individual (Fretwell \& Lucas, 1970). Why this should be so is easy to understand at an intuitive level: If one site provides higher gains than the others, optimal foragers should, by hypothesis, move to this site; as a result, however (see

The data of the 20-subject group were part of a poster on the ideal free distribution, presented at the 1996 annual meeting of ARC (Association pour la Recherche Cognitive). We thank Claudine Bover, Bruno Broutin, Fabrice Clin, Karine Gravelin, and Jean-Louis Monestes for their help in running the experiments. We also thank William Baum, Franck Cézilly, Reid Hastie, Joel Myerson, and an anonymous reviewer for their comments on the manuscript. The data set of individual subjects can be obtained from M. Sokolowski, Faculté de Philosophie, Sciences Humaines et Sociales, Université de Picardie-Jules Verne, Campus rue Solomon Mahlangu, 80025 Amiens Cédex 1, France (e-mail: msokolowski@ nordnet.fr). above), their gains in this site would drop until they reached the level of the gains obtained elsewhere. The optimal, equilibrium distribution of animals is thus one with equal gains in all sites.

The simplest test of this ideal free distribution involves continuous input procedures, where depletion in a site is prevented by the constant arrival of new resource items (e.g., Harper, 1982). Assuming that resources are simply shared among equal competitors, in any site $i$ each individual's gain is $W_{i} / n_{i}$, where $W_{i}$ is the total amount (or rate) of resources in site $i$ and $n_{i}$ is the number of individuals present in this site. With two sites, $i$ and $j$, at the equilibrium, the ideal free model yields $W_{i} / n_{i}=W_{j} / n_{j}$ (equality of gains), or equivalently:

$$
n_{i} / n_{j}=W_{i} / W_{j}
$$

This relation is usually termed habitat matching (see Pulliam \& Caraco, 1984); the relative number of competitors present at two sites, $n_{i} / n_{j}$, should match the relative amount (or rate) of resources available in these sites, $W_{l} / W_{j}{ }^{1}$

It is important to realize that habitat matching may be achieved through different means in different species or animals (cf. Milinski, 1984, p. 241). For example, Equation 1 may result from each animal's allocating its time among sites in proportion to the rates of resources observed (Gallistel, 1993, pp. 353-359) or consumed (Cézilly \& Boy, 1991; Harley, 1981) in these sites. Alternatively, each animal's behavior may drift toward the site with the highest $W_{i} / n_{i}$ quantity (Vaughan, 1981; see Herrnstein, 1990). The relations of these choice processes to each other and 
to the optimization of gains underlying the ideal free model have been the focus of much argument (e.g., Commons, Herrnstein, \& Rachlin, 1982; Houston \& Sumida, 1987; Mazur, 1981; Staddon \& Hinson, 1983). Independently of the exact mechanisms involved, however, the ideal free distribution remains a useful tool for relating biological and psychological approaches (e.g., Gallistel, 1993; Gray, 1994; Kraft \& Baum, 1996).

In an ecological context, Equation 1 has been tested with animal species such as ducks, fishes, or ants exploiting food resources (e.g., Godin \& Keenleyside, 1984; Harper, 1982; Lamb \& Ollason, 1993; see Tregenza, 1995). Although various correlational data suggest that habitat matching or some variant of it applies to human populations (Cashdan, 1992; Gillis, Peterman, \& Tyler, 1993; Whitehead \& Hope, 1990), there currently is no experimental test of the ideal free distribution in humans. We have recently tested Equation 1 with human subjects competing for money.

\section{METHOD}

A group of 15 adults were seated at small tables arranged in a circle (about $5.5 \mathrm{~m}$ in diameter). Each table had a holder for one of two cardboard signs $(20 \times 20 \mathrm{~cm})$, one green and one red. Each subject was assigned an arbitrary identification number between 1 and 15 and each had at his (her) disposal a container of 110 metallic tokens engraved with this number. Before starting the experiment, each subject received a sheet of paper with the following instructions (here translated from the French):

You are going to take part in an approximately 3-hour-long series of five games. Your goal is to earn money. The maximal amount you can get is 52 francs per game (the maximal amount for the whole session being 260 francs). You may neither talk nor ask questions.

You have two signs (one red and one green) at your disposal. On each trial, you are to choose either the green or the red sign and display it to the whole group by putting this sign on your holder. You may not change your sign after the tone.

The tokens engraved with your identification number will allow us to randomly draw the winners, whose numbers will be distinctly announced to the whole group. You'll win one point if your token is drawn. The person accumulating the highest number of points at the end of a game will earn 52 francs.

We'll start with 10 warm-up trials without drawings.

No other instructions were provided. Once read, each sheet had to be returned to the experimenter. Once all sheets had been collected, the experiment began.

The experiment took place in discrete trials. On each trial, in conformity with the instructions, each subject had to choose one of his (her) two signs, either the green or the red one, and expose it on his (her) holder; the color of the chosen sign could thus be seen by all in the group. The subjects were free to change their choices more than one time before the end of the trial. Within each trial, however, following a short period of choice adjustments, the subjects stopped handling their signs; after $6 \mathrm{sec}$ without any sign change, a tone signaled the end of the trial. The experimenter then collected one token per subject; the tokens of the $n_{\mathrm{G}}$ subjects presenting a green sign were collected in a green box, and the tokens of the $n_{R}$ subjects presenting a red sign were collected in a red box $\left(n_{G}+n_{R}=15\right)$. The exposed signs were also removed from their holders and put back on the tables.

The experiment started with a control phase of 10 trials without any drawing; this was followed by five experimental phases or "games" of 20 trials each. At the end of each trial in a game, 10 to- kens were drawn in front of the whole group, $W_{\mathrm{G}}$ tokens being drawn at random from the green box, and $W_{\mathrm{R}}$ tokens being drawn at random from the red box $\left(W_{\mathrm{G}}+W_{\mathrm{R}}=10\right) .{ }^{2}$ The identification numbers on these 10 winning tokens (corresponding to 10 different subjects) were then announced to the group. For each trial in Game $1, W_{\mathrm{G}}=6, W_{\mathrm{R}}=4$; in Game $2, W_{\mathrm{G}}=1, W_{\mathrm{R}}=9$; in Game $3, W_{\mathrm{G}}=8, W_{\mathrm{R}}=2$; in Game $4, W_{\mathrm{G}}=3, W_{\mathrm{R}}=7$; in Game 5 , $W_{\mathrm{G}}=5, W_{\mathrm{R}}=5$. At the end of each game, in conformity with the instructions, the subject with the highest number of winning choices earned 52 French francs.

The sign colors (green and red) may be seen as analogous to two distinct sites with limited resource amounts, $W_{\mathrm{G}}$ and $W_{\mathrm{R}}$. Choosing a color was thus analogous to entering one site. Our procedure ensured freedom of choice and, because of the random draws, equal competitiveness for all subjects (see Equation 2 below). Also, traveling costs were eliminated. The experimental situation thus permitted a fair and simple test of the ideal free model (Fretwell \& Lucas, 1970). ${ }^{3}$ The average individual gains in the green and red "sites" were $W_{\mathrm{G}} / n_{\mathrm{G}}$ and $W_{\mathrm{R}} / n_{\mathrm{R}}$, respectively. At the equilibrium, the ideal free distribution yields $W_{\mathrm{G}} / n_{\mathrm{G}}=W_{\mathrm{R}} / n_{\mathrm{R}}$, or

$$
n_{\mathrm{G}} / n_{\mathrm{R}}=W_{\mathrm{G}} / W_{\mathrm{R}}
$$

for each game.

\section{RESULTS AND DISCUSSION}

Figure 1 shows how the proportion of subjects choosing the green color evolved during the experiment. The average proportion during the first 10 control trials was close to .50 (exact value: .43), although the raw data displayed much variability from trial to trial. The proportion of subjects choosing green during each game was evidently sensitive to the current resource distribution (Figure 1); however, equilibrium proportions only approximated the ideal free predictions (dashed horizontal lines). To better ascertain the relation between group distribution and resource ratios, Equation 2 was replaced by:

$$
n_{\mathrm{G}} / n_{\mathrm{R}}=b\left(W_{\mathrm{G}} / W_{\mathrm{R}}\right)^{c},
$$

where $b$ measures a group bias in favor of choosing green and the exponent $c$ is an index of sensitivity to resource ratios (see Fagen, 1987; Kennedy \& Gray, 1993). We actually evaluated Equation 3 in its logarithmic form; that is,

$$
\ln \left(n_{\mathrm{G}} / n_{\mathrm{R}}\right)=c \ln \left(W_{\mathrm{G}} / W_{\mathrm{R}}\right)+\ln (b) .
$$

Linear regression of $\ln \left(n_{\mathrm{G}} / n_{\mathrm{R}}\right)$ on $\ln \left(W_{\mathrm{G}} / W_{\mathrm{R}}\right), n_{\mathrm{G}}$ and $n_{\mathrm{R}}$ being averaged over the last five trials of each game, revealed a near absence of bias but a sensitivity below 1 (Figure 2; $b=1.03, c=0.67, r^{2}=.99$ ).

We replicated this experiment on a group of 10 subjects, with black and white signs and six winning tokens per trial (for ease of exposition, we shall keep our previous notation and subscripts, treating black as identical to green and white as identical to red). Because of time limitations, only three distinct $W_{\mathrm{G}} / W_{\mathrm{R}}$ values could be tested, the initial 10 warm-up trials being followed by three games of 25 trials each. For each trial in Game $1, W_{\mathrm{G}}=1, W_{\mathrm{R}}=5$; in Game 2, $W_{\mathrm{G}}=4, W_{\mathrm{R}}=2$; in Game 3, $W_{\mathrm{G}}=3, W_{\mathrm{R}}=3$. At the end of each game, the subject with the highest number of winning choices earned 35 French francs. The gen- 


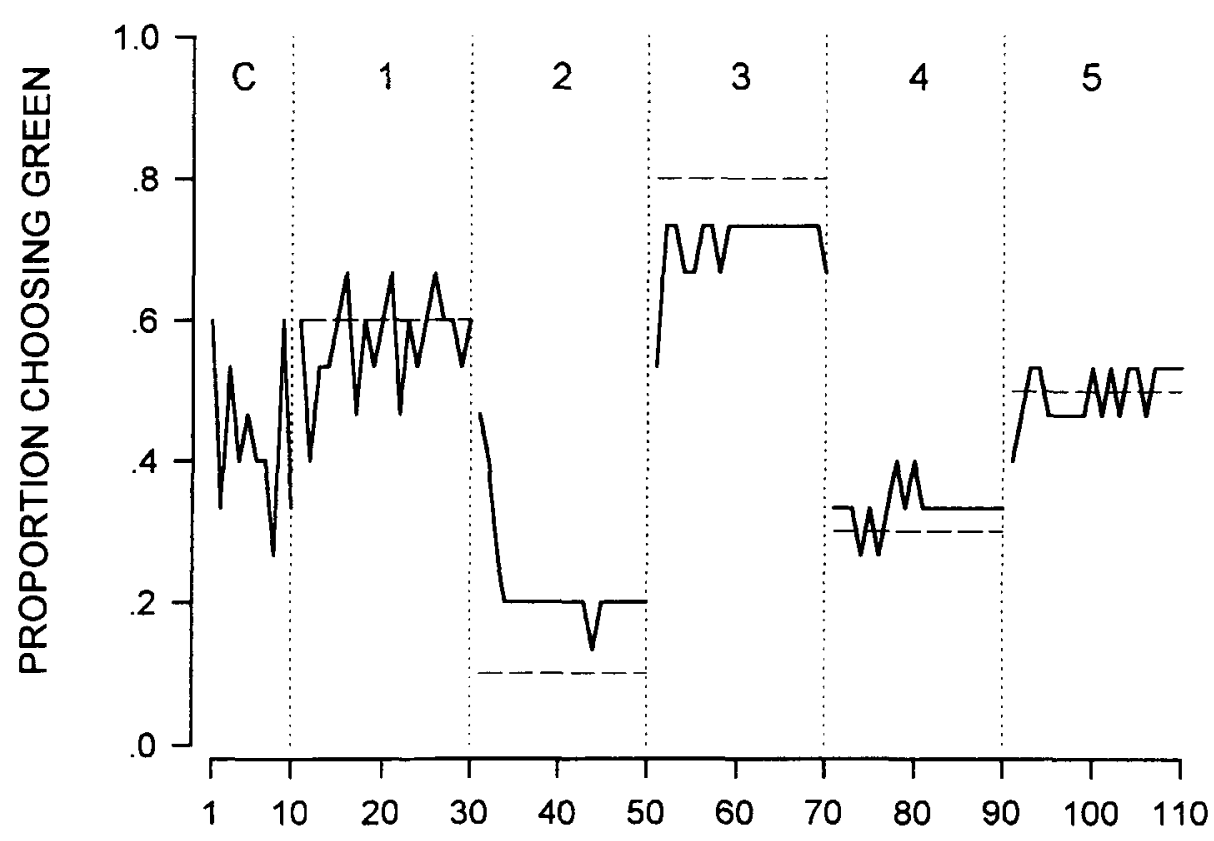

\section{TRIALS}

Figure 1. Proportion of subjects choosing green $\left(n_{G} / 15\right)$ as a function of trial number (solid lines). Dotted vertical lines indicate transitions between phases $(C=$ control phase; numbers from 1 to 5 indicate successive games). Dashed horizontal lines indicate the ideal free predictions for each game (cf. Equation 2).

eral procedure was otherwise identical to that of the 20subject experiment, instructions being, of course, suitably adjusted with respect to sign colors, number of games, winning amount per game, and overall duration of the experiment. We obtained largely similar results with respect to the quality of adjustment across phases and the sensitivity of group distribution to resource ratios (see Figure 3, top panel; $b=1.03, c=0.70, r^{2}=.99$ ).

A further replication was carried out on a group of 20 subjects, with black and white signs and 12 winning tokens on each trial. The initial 10 warm-up trials were followed by three games of 25 trials each. For each trial in Game $1, W_{\mathrm{G}}=2, W_{\mathrm{R}}=10$; in Game $2, W_{\mathrm{G}}=8$, $W_{\mathrm{R}}=4$; in Game 3, $W_{\mathrm{G}}=6, W_{\mathrm{R}}=6$. At the end of each game, the 2 subjects with the highest numbers of winning choices earned 35 French francs each. ${ }^{4}$ The general procedure was otherwise identical to that of the 10 - and 15-subject experiments, instructions being suitably adjusted with respect to sign colors, number of games, number of winners, winning amount per game, and overall duration of the experiment. The results again proved similar to those previously obtained, with a sensitivity to resource ratios of 0.62 (Figure 3 , bottom panel; $b=1.17$, $c=0.62, r^{2}=.98$ ). Exponents of comparable values, with a median $c$ of 0.66 , have been observed in animal studies (Kennedy \& Gray, 1993).

Various mechanisms have been proposed to explain this kind of departure from habitat matching (see Ken- nedy \& Gray, 1993; Tregenza, 1995). Explanations in terms of "foraging interference" (such as resource wasting; Sutherland, 1983) or differing competitive abilities (Houston \& McNamara, 1988) cannot apply here, due to the procedure used. Examination of the raw data, however, revealed a simple property of the behavioral process operative in our situation. In each game, the subjects' choices

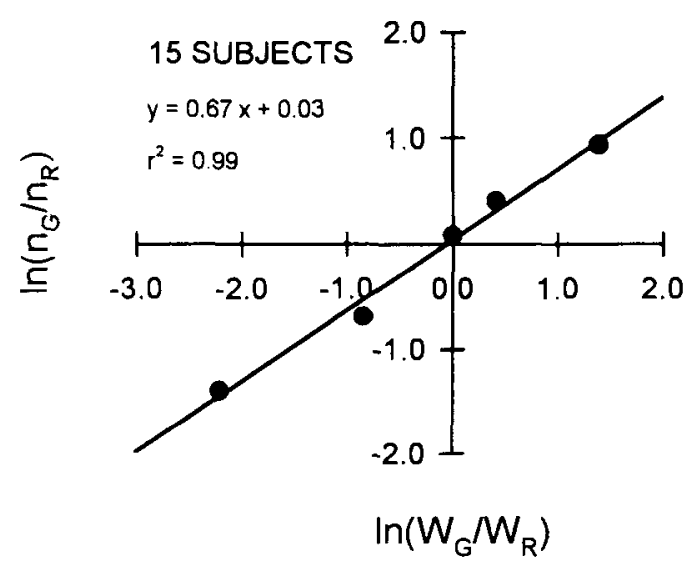

Figure 2. Double logarithmic plot of Equation 3. Each data point corresponds to one game $\left(n_{G}\right.$ and $n_{R}$ being averaged over the last five trials of a game). Linear regression of $y=\ln \left(n_{G} / n_{R}\right)$ on $x=\ln \left(W_{\mathrm{G}} / W_{\mathrm{R}}\right)$ yielded a best-fitting slope of 0.67 and an intercept of 0.03 (Equation 3 , with $c=0.67$ and $b=1.03 ; r^{2}=0.99$ ). 
tended to equalize the numbers of losing tokens across sites $\left(n_{\mathrm{G}}-W_{\mathrm{G}}=n_{\mathrm{R}}-W_{\mathrm{R}}\right)$. This resulted in the relation:

$$
n_{\mathrm{G}}-n_{\mathrm{R}}=W_{\mathrm{G}}-W_{\mathrm{R}},
$$

whose fit to the data (pooled over the main experiment and its two replications) is shown in Figure 4. Equation 4 implies that the $n_{\mathrm{G}} / n_{\mathrm{R}}$ ratio equals $\left(W_{\mathrm{G}}-W_{\mathrm{R}}+n\right) /$ $\left(W_{\mathrm{R}}-W_{\mathrm{G}}+n\right)$, where $n$ is the total number of subjects in the experiment. When $W_{\mathrm{G}}=W_{\mathrm{R}}, n_{\mathrm{G}}=n_{\mathrm{R}}$; when $W_{\mathrm{G}}<W_{\mathrm{R}},\left(n_{\mathrm{G}} / n_{\mathrm{R}}\right)>\left(W_{\mathrm{G}} / W_{\mathrm{R}}\right)$; when $W_{\mathrm{G}}>W_{\mathrm{R}},\left(n_{\mathrm{G}} / n_{\mathrm{R}}\right)<$ $\left(W_{\mathrm{G}} / W_{\mathrm{R}}\right)$. Equalizing the numbers of losing tokens across sites thus predicts an absence of bias and a best-fitting sensitivity below 1 in Equation 3, as was observed.

A possible dynamic process for Equation 4 is that each subject avoids the color with the highest number of losing tokens. This amounts to choosing the site with the

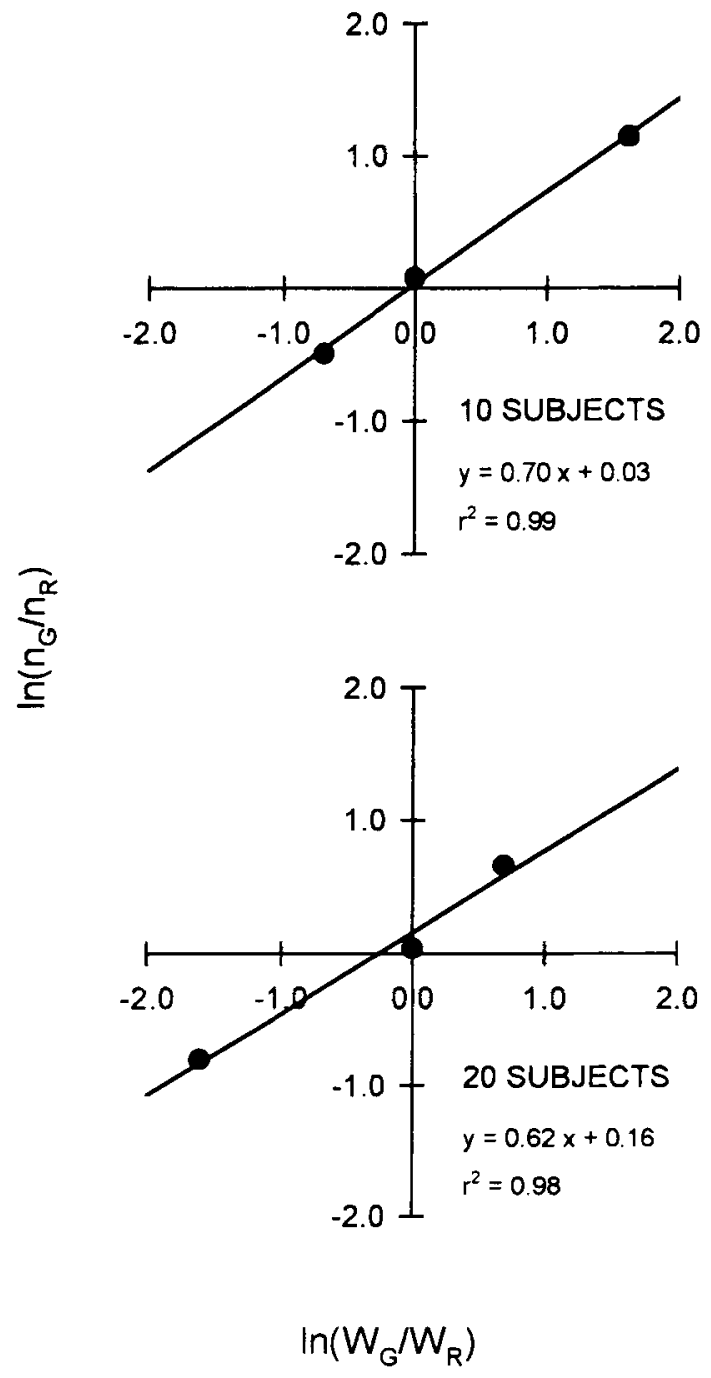

Figure 3. Top panel: 10-subject replication. Best fit: $b=1.03$, $c=0.70, r^{2}=0.99$. Bottom panel: 20-subject replication. Best fit: $b=1.17, c=0.62, r^{2}=0.98$. Same conventions as in Figure 2.

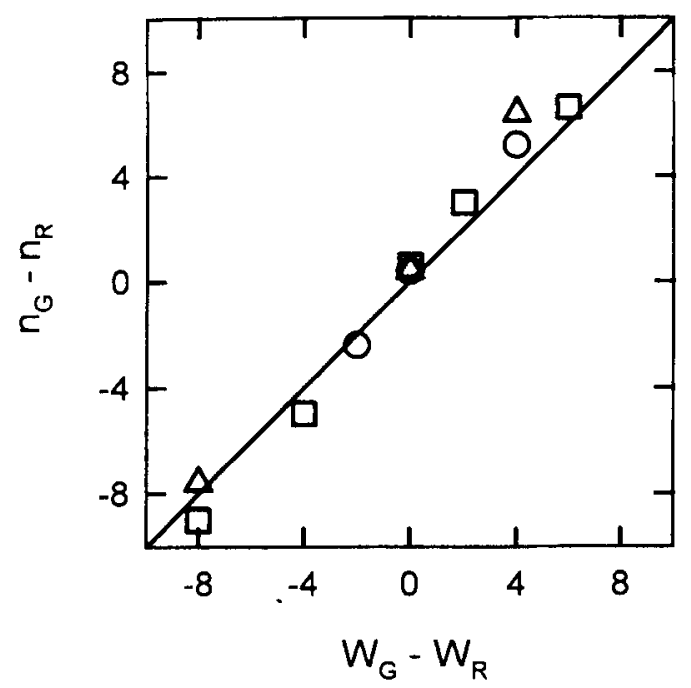

Figure 4. General fit of Equation 4. The data from the experiments with 15,10 , and 20 subjects are indicated by squares, circles, and triangles, respectively. Equation 4, represented by the diagonal line $\left(n_{\mathrm{G}}-n_{\mathrm{R}}=W_{\mathrm{G}}-W_{\mathrm{R}}\right)$, accounts for $96 \%$ of the whole variance.

highest difference, $W_{i}-n_{i}$, instead of choosing the site with the highest ratio, $W_{i} / n_{i}$ (notice that both quantities are increasing in $W_{i}$ and decreasing in $n_{i}$ ). In our experiment, rapid adjustments to changes in $W_{i}-n_{i}$ required the subjects' behavior to be sensitive to numerical attributes of the environment (cf. Honig, 1993), and, indeed, throughout experimental trials, our subjects abundantly observed each others' signs.

Individual data showed a wide variety of different patterns. Computed over all trials in a game, for example, the percentages of "green" choices often varied from 0 to 1 across subjects. Some subjects kept choosing the same color (either green or red) during the whole game, while some changed their choices on almost every trial, and other subjects showed yet other patterns of responding. At the equilibrium, however, when, from one trial to another, a subject changed the color of his or her sign, another subject would often make the inverse adjustment, the net result being that the number of subjects choosing green did not vary.

Evidently, a dynamic process of difference equalization is only one of the ways in which approximate adherence to the ideal free distribution (Equation 3 with $c<1$ ) could be achieved. The fit of Equation 4 to the data is quantitatively satisfactory (percentage of variance accounted for $96 \%$ ), whereas the existence of small departures from the predictions (see Figure 4) suggests that the proposed principle should remain tentative and await further replications. In any event, the observed similarity of behavioral outcomes across species points to the usefulness of the ideal free model and its developments for understanding human performance in competitive settings. 


\section{REFERENCES}

CaShDan, E. (1992). Spatial organization and habitat use. In E. A. Smith \& B. Winterhalder (Eds.), Evolutionary ecology and human behavior (pp. 237-266). New York: Aldine de Gruyter.

CÉZILlY, F, \& BOY, V. (1991). Ideal free distribution and individual decision rules: A Bayesian approach. Acta Ecologia, 12, 403-410.

Charnov, E. L. (1976). Optimal foraging, the marginal value theorem. Theoretical Population Biology, 9, 129-136.

Commons, M. L., Herrnstein, R. J., \& Rachlin, H. (Eds.) (1982). Quantitative analyses of behavior: Vol. 2. Matching and maximizing accounts. Cambridge, MA: Ballinger.

DAVISON, M., \& MCCARTHY, D. (1988). The matching law: A research review. Hillsdale, $\mathrm{NJ}$ : Erlbaum.

FAGEN, R. (1987). A generalized habitat matching rule. Evolutionary Ecology, 1, 5-10.

Fretwell, S. D., \& LuCAS, H. L., JR. (1970). On territorial behavior and other factors influencing habitat distribution in birds. Acta Biotheoretica, 19, 16-36.

Gallistel, C. R. (1993). The organization of learning. Cambridge, MA: MIT Press.

Gillis, D. M., Peterman, R. M., \& Tyler, A. V. (1993). Movement dynamics in a fishery: Application of the ideal free distribution to spatial allocation of effort. Canadian Journal of Fisheries \& Aquatic Sciences, 50, 323-333.

Godin, J.-G. J., \& KeENLEYside, M. H. A. (1984). Foraging on patchily distributed prey by a cichlid fish (Teleostei, Cichlidae): A test of the ideal free distribution theory. Animal Behaviour, 32, 120-131.

GRAY, R. D. (1994). Sparrows, matching and the ideal free distribution: Can biological and psychological approaches be synthesized? Animal Behaviour, 48, 411-423.

HARLEY, C. B. (1981). Learning the evolutionary stable strategy. Journal of Theoretical Biology, 89, 611-633.

HARPER, D. G. C. (1982). Competitive foraging in mallards: "Ideal free" ducks. Animal Behaviour, 30, 575-584.

Hassell, M. P., \& VArLey, G. C. (1969). New inductive population model for insect parasites and its bearing on biological control. $\mathrm{Na}$ ture, 223, 1133-1137.

Herrnstein, R. J. (1990). Behavior, reinforcement and utility. Psychological Science, 1, 217-224.

HoNiG, W. K. (1993). Numerosity as a dimension of stimulus control In S. T. Boysen \& E. J. Capaldi (Eds.), The development of numerical competence: Animal and human models (pp. 61-86). Hillsdale, NJ: Erlbaum.

Houston, A. I., \& MCNAMARA, J. M. (1988). The ideal free distribution when competitive abilities differ: An approach based on statistical mechanics. Animal Behaviour, 36, 166-174.

Houston, A. I., \& SUmIDA, B. H. (1987). Learning rules, matching and frequency dependence. Journal of Theoretical Biology, 126, 289-308.

KenNEDY, M., \& GRAY, R. D. (1993). Can ecological theory predict the distribution of foraging animals? A critical analysis of experiments on the Ideal Free Distribution. Oikos, 68, 158-166.

Kraft, J., \& BauM, W. M. (1996, May). Choice in a flock of pigeons:
Testing the ideal free distribution. Paper presented at the annual meeting of the Society of the Quantitative Analyses of Behavior, San Francisco.

LAMB, A. E., \& OlLaSON, J. G. (1993), Foraging wood-ants Formica aquilonia Yarrow (Hymenoptera: Formicidae) tend to adopt the ideal free distribution. Behavioural Processes, 28, 189-198.

MAZUR, J. E. (1981). Optimization theory fails to predict performance of pigeons in a two-response situation. Science, 214, 823-825.

MILINSKI, M. (1984). Competitive resource sharing: An experimental test of a learning rule for ESSs. Animal Behaviour, 32, 233-242.

Pulliam, H. R., \& CARACo, T. (1984). Living in groups: Is there an optimal group size? In J. R. Krebs \& N. B. Davies (Eds.), Behavioural ecology: An evolutionary approach (2nd ed., pp. 122-147). Oxford: Blackwell.

Sraddon, J. E. R., \& Hinson, J. M. (1983). Optimization: A result or a mechanism? Science, 221, 976-977.

SutherLand, W. J. (1983). Aggregation and the "ideal free" distribution. Journal of Animal Ecology, 52, 821-828.

SutherLAND, W. J. (1996). From individual behaviour to population ecology. Oxford: Oxford University Press.

Tregenza, T. (1995). Building on the ideal free distribution. In A. H. Fitter \& M. Begon (Eds.), Advances in ecological research (Vol. 26, pp. 253-307). New York: Academic Press.

VAUGHAN, W., JR. (1981). Melioration, matching, and maximization. Journal of the Experimental Analysis of Behavior, 36, 141-149.

WhiteHEAd, M., \& Hope, P. L. (1990). Sperm whalers off the Galápagos islands and in the Western North Pacific, 1830-1850: Ideal free whalers? Ethology \& Sociobiology, 12, 147-161.

\section{NOTES}

1. Habitat matching (our Equation 1) should not be confused with the relation known in behavioral psychology as the matching law (see Davison \& McCarthy, 1988). Equation 1 is defined at the group level and deals with the number of individuals occupying one site, whereas the matching law applies to an individual's numbers of responses and reinforcers. Obtaining habitat matching at the group level in no way implies that the individuals' choices followed the matching law, although of course they may (cf. Gray, 1994).

2. For a given color, if the number of collected tokens was below the programmed number of winners for this color, the experimenter simply drew all of the collected tokens. This happened only one time in the experiment.

3. Although common in other contexts (e.g., Charnov, 1976), the hypothesis of travelling costs is not part of Fretwell and Lucas's (1970) original model. Traveling costs may actually induce systematic departures from the ideal free distribution (see Kennedy \& Gray, 1993).

4. The theoretical, average gain per subject and per game was thus close or equal to 3.50 French francs in all of the three experiments.

(Manuscript received June 5, 1997; revision accepted for publication April 13, 1998.) 